\title{
INSPEÇÃO E ANÁLISE ESTRUTURAL DE UMA TRELIÇA MISTA DE CONCRETO ARMADO E AÇO EM UMA EDIFICAÇÃO INDUSTRIAL
}

\author{
L.A. REGINATO \\ Engenheiro Civil \\ LEME/UFRGS \\ RS; Brasil \\ lucas.reginato@ufrgs.br \\ D. SEVERO DA SILVA \\ Engenhario Civil \\ RS; Brasil
}

\author{
J. L. CAMPAGNOLO \\ Engenhario Civil \\ LEME/UFRGS \\ RS; Brasil \\ campagnolo@cpgec.ufrgs.br
}

\author{
A. LORENZI \\ Engenheiro Civil \\ LEME/UFRGS \\ RS; Brasil \\ alexandre.lorenzi@ufrgs.br \\ D. L. KLEIN \\ Engenheiro Civil \\ LEME/UFRGS \\ RS; Brasil \\ dariolklein@gmail.com
}

\author{
J. ALMEIDA \\ Engenheiro Civil \\ LEME/UFRGS \\ RS; Brasil \\ jasscarnival@gmail.com
}

\section{RESUMO}

Para garantir a durabilidade das estruturas de concreto armado, estas devem ser submetidas a inspeções e manutenções periódicas. Através da inspeção é possível identificar mecanismos de degradação que podem comprometer o desempenho, reduzir a vida útil ou, em último caso, provocar a perda da estabilidade da estrutura. Em edificações industriais, cujo o objetivo principal dentro de uma indústria é o cumprimento de metas de produção, a implementação e manutenção de um plano de inspeções e manutenções programadas (PIM) nem sempre é facil de concretizar, visto que em algumas situações é necessário a interrupção do processo produtivo. A ausência de um PIM adequado pode agravar as manifestações patológicas existentes nas estruturas, em especial, aquelas que estão submetidas a ambientes agressivos. Este trabalho apresenta os resultados de uma vistoria realizada na estrutura de concreto armado da cobertura de uma planta industrial, com o objetivo de verificar as condições atuais de conservação e registrar as principais manifestações patológicas existentes. Complementarmente, foi realizada a verificação estrutural teórica, para avaliar a capacidade portante da estrutura. Os resultados evidenciam a importância da inspeção e da verificação estrutural, de forma a poder melhorar o atual nível de desempenho e prolongar a vida útil da estrutura.

Palavras-chave: Reforço, Inspeção, Estruturas de Concreto.

\section{ABSTRACT}

To guarantee the durability of reinforced concrete structures, they must be subjected to periodic inspections and maintenance. Through inspection, it is possible to identify degradation mechanisms that can compromise performance, reduce service life or, ultimately, cause the loss of structure stability. In industrial buildings, whose main objective is the fulfillment of production targets, the implementation and maintenance of a plan for periodic inspections and maintenance (PIM), it is not always easy to achieve, since in some situations it is necessary the interruption of the production process. The absence of an adequate PIM can aggravate the pathological manifestations that exist in the structures, especially those that are subjected to aggressive environments. This work presents the results of an inspection carried out on the reinforced concrete structure of the roof of an industrial plant, with the objective of verifying the current conditions of conservation and recording the main existing pathological manifestations. In addition, theoretical structural verification was carried out to assess the bearing capacity of the structure. The results show the importance of inspection and structural verification, in order to improve the current level of performance and extend the life of the structure.

Keywords: reinforcement, overhaul, Concrete Structures. 


\section{INTRODUÇÃO}

Para garantir a durabilidade das estruturas de concreto armado, estas devem ser submetidas a inspeções e manutenções periódicas. A norma ABNT NBR 16230:2013[1], da Associação Brasileira de Normas Técnicas, especifica requisitos tanto para a inspeção de estruturas de concreto, quanto de qualificação e certificação de pessoal habilitado a inspecionálas.

Através da inspeção é possível identificar mecanismos de degradação que podem comprometer o desempenho, reduzir a vida útil ou até mesmo provocar a perda da estabilidade da estrutura. Em edificações industriais, cujo o objetivo principal dentro de uma indústria é o cumprimento de metas de produção, a implementação e manutenção de um plano de inspeções e manutenções periódicas (PIM), nem sempre é facil de concretizar, visto que em algumas situações é necessário a interrupção do processo produtivo. A ausência de um PIM adequado pode agravar as manifestações patológicas existentes nas estruturas, em especial, aquelas que estão submetidas a ambientes agressivos.

De acordo com Dal Molin [2], a corrosão é a principal manifestação em estruturas de concreto armado em edificações no Rio Grande do Sul. Causcudo e Helene [3] e Meira [4] destacam a despassivação por carbonatação e a despassivação por presença de cloretos como os principais mecanismos de deterioração relativos às armaduras de aço. Na carbonatação, o gás carbônico presente na atmosfera penetra por difusão nos poros do concreto e reage com os hidróxidos alcalinos reduzindo o $\mathrm{pH}$. A despassivação por carbonatação só ocorre de maneira significativa em ambientes de umidade relativa abaixo de $98 \%$ e acima de $60 \%$, possibilitando a ocorrência da corrosão das armaduras. A penetração de ions cloretos ocorre através de processos de difusão, de impregnação ou de absorção, sendo que, acima de determinados níveis, pode provocar a despassivação da superfície do aço e a ocorrência de corrosão. A coorosão pode ser indentificada visualmente através do aparecimento de manchas, fissuras, destacamentos de pedaços de concreto e perda da secção resistente e da aderência das barras de aço, promovendo o colapso da estrutura ou de suas partes.

Em treliças mistas de concreto armado e aço, onde o aço exerce o papel de tirante, reforçando a resistência da estrutura aos esforços de tração, a ocorrência de corrosão no reforço de aço poderá provocar a redução significativa da capacidade portante, incluindo a perda de estabilidade e por fim o colapso da estrutura.

Este trabalho apresenta os resultados de uma vistoria visual realizada na estrutura de concreto armado da cobertura de uma planta industrial, para verificar as condições atuais de conservação e registrar as principais manifestações patológicas existentes. Complementarmente, foi realizada a verificação estrutural teórica, segundo a norma ABNT NBR 6118:2014 [5], para avaliar a capacidade portante da estrutura.

\section{DESCRIÇÃO DA ESTRUTURA E METODOLOGIA DE INSPEÇÃO}

O escopo da vistoria englobou a análise dos elementos da estrutura de sustentação de uma cobertura em uma edificação industrial, cujo o ambiente possui uma agressividade elevada devido aos processos industriais utilizados. A edificação possui aproximadamente $12.000 \mathrm{~m}^{2} \mathrm{com} 150 \mathrm{~m}$ de comprimento e $80 \mathrm{~m}$ de largura. A cobertura da edificação é no formato de Sheed's com vão entre as treliças de sustentação de $10 \mathrm{~m}$ (Figura 1). A edificação foi executada em diferentes etapas de construção, conforme apresentado na Figura 1.

A treliça de sustentação da cobertura é composta por três vãos apoiados sobre pilares extremos, cada vão corresponde a um setor da linha de produção da fábrica designados como Setor I, Setor II e Setor III, possuindo os respectivos vãos livres 24,50 m, 26,25 m e 30,26 m, conforme apresentado na Figura 1. As treliças localizadas nos Setores I e II são treliças contínuas (hiperestáticas), apoiadas sobre 3 pilares de sustentação, entretanto as treliças localizadas no Setor III são treliças simplesmente apoiada sobre dois pilares (isostáticas). 


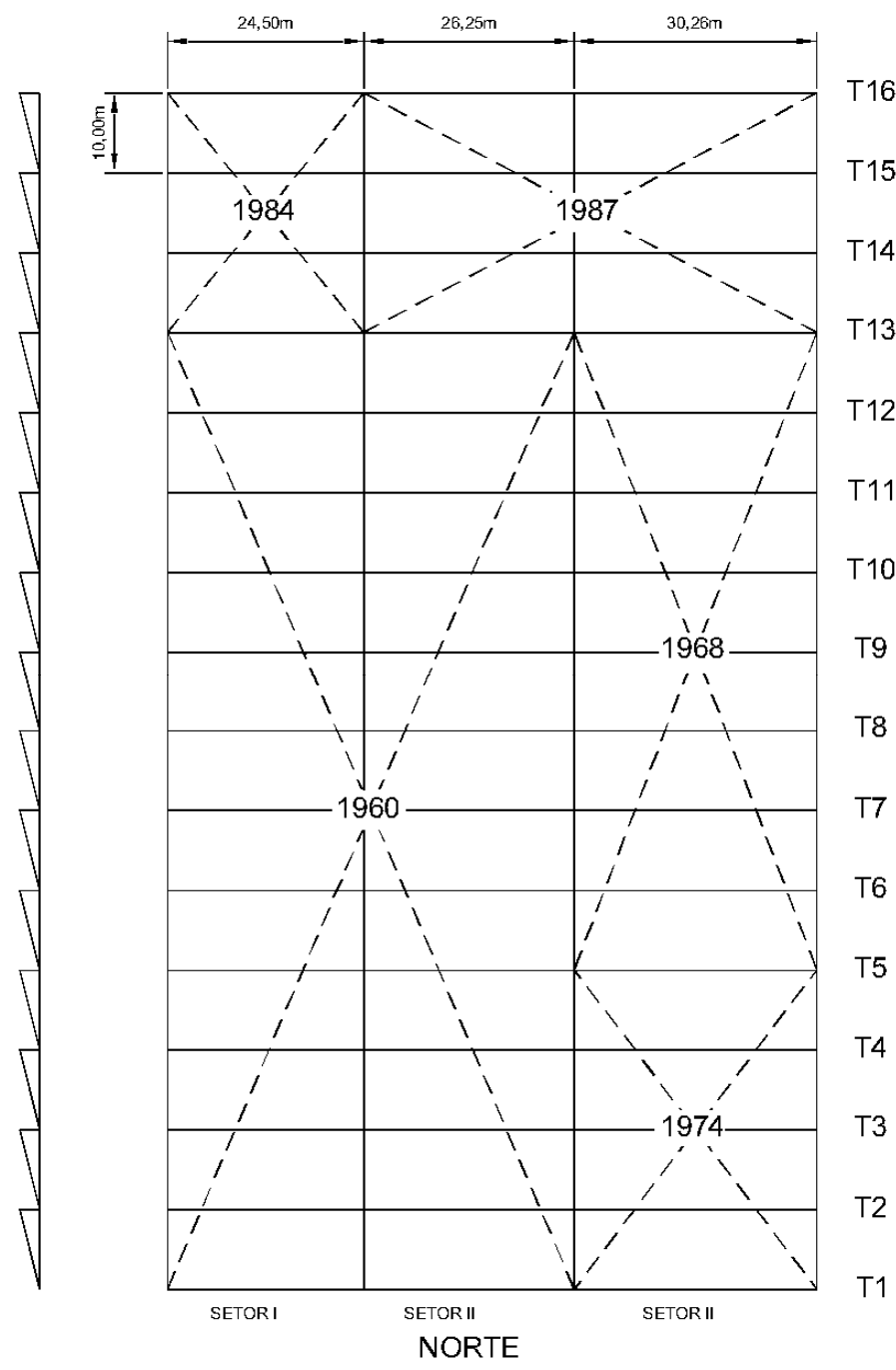

Figura 1: Localização e ano e execução da estrutura da cobertura.

As treliças localizadas nos Setores I e II, vistoriadas em anos anteriores e, na época, constatou-se que as mesmas foram montadas como contínuas, porém elas foram concebidas inicialmente como estruturas independentes (isostáticas). Este fato acarretou uma inversão de esforços nas solicitações normais de algumas barras, as quais foram reforçadas posteriormente com tirantes metálicos, fixados em chapas metálicas ancoradas nos nós da treliça. O modelo da treliça está apresentado na Figura 2, com indicação dos elementos metálicos (vermelho) das treliças e a localização dos setores.

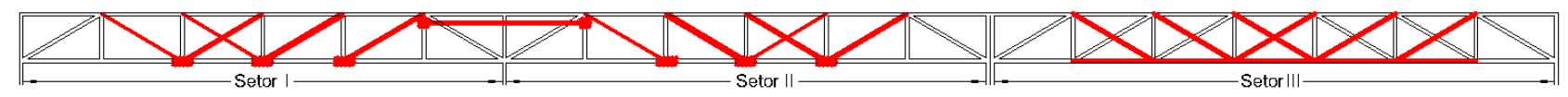

Figura 2: Representação da treliça de sustentação da cobertura.

\subsection{Metodologia de inspeção}

A inspeção da estrutura de sustentação da cobertura foi realizada através de uma inspeção visual detalhada das estruturas que compõem a cobertura: Treliças, Tesouras, Terças e Tirantes de Contraventamento. Por tratar-se de uma estrutura mista (concreto armado e aço) inicialmente foi realizado a inspeção nos segmentos de concreto armado e posteriormente nos elementos metálicos e de madeira. Tendo como foco desse trabalho o levantamento das manifestações nos elementos metálicos, na inspeção foi levantado o quadro de manifestações patológicas, incluindo: oxidação, corrosão, corrosão com redução de seção e rompimento por corrosão, para elementos metálicos. 
Durante o levantamento verificou-se que um dos tirantes que compõem a Treliça 4 no Setor III, possuía uma redução de $32 \%$ da seção transversal devido ao processo corrosivo, desta forma a fim de verificar a condições de segurança e possível necessidade de reforço da treliça foi realizada uma verificação teórica da capacidade portante da estrutura. Como a treliça em questão é segmentada do restante da treliça (Setor III) e simplesmente apoiada sobre dois pilares, realizou-se uma análise linear, considerando a treliça simplesmente apoiada. A descrição do segmento analisado da Treliça 4 está descrito nos itens seguintes.

\subsection{Descrição da treliça analisada}

A Treliça 4, no Setor III, foi construída no ano de 1974, conforme mostrado na Figura 1. Trata-se de uma treliça de concreto armado com 30 metros de vão e 2,82 metros de altura. A cobertura do prédio, nesta região, é suportada treliças, espaçadas entre si de 10 metros, simplesmente apoiadas em dois pilares extremos, que foram reforçadas com tirantes metálicos no ano de 1993.

A estrutura suporta uma cobertura de telhas de fibrocimento com $8 \mathrm{~mm}$ de espessura, cuja carga é transferida por terças de concreto armado, de seção retangular $(0,10 \times 0,30) \mathrm{m}^{2}$, simplesmente apoiadas em tesouras de concreto armado, de seção $0,026 \mathrm{~m}^{2}$.

A estrutura treliçada, em questão, é constituída por barras de concreto armado de seção retangular de $(0,20 x 0,20) \mathrm{m}^{2}$ no banzo superior, banzo inferior, montantes e nas duas diagonais externas, assim como, calha de concreto armado com seção composta no banzo inferior, com área equivalente a $0,055 \mathrm{~m}^{2}$, reforçada por 2 chapas de aço de $(0,044 \times$ x 0,016$)$ $\mathrm{m}^{2}$, e tirantes de aço nas diagonais internas, exceto no quadro central, constituídos por 1 barra de seção circular $\varnothing 25 \mathrm{~mm}$ (1 Ø $25 \mathrm{~mm})$ em CA-50, reforçados por 2 chapas de aço de $(0,044 \times 0,016) \mathrm{m}^{2}$. No quadro central as diagonais são constituídas por 4 chapas de aço de dimensões $(0,044 \times 0,016) \mathrm{m}^{2}$. Todas as armaduras, exceto as barras de aço dos tirantes, são em aço liso (CA-24). Os dados das dimensões, armaduras e reforços dos elementos componentes da treliça foram obtidos em relatórios de inspeções anteriores e projeto estrutural da mesma. Na recente inspeção da estrutura, foi constatada redução da seção de aço, devida a corrosão, do tirante localizado na diagonal indicada na Figura 3.

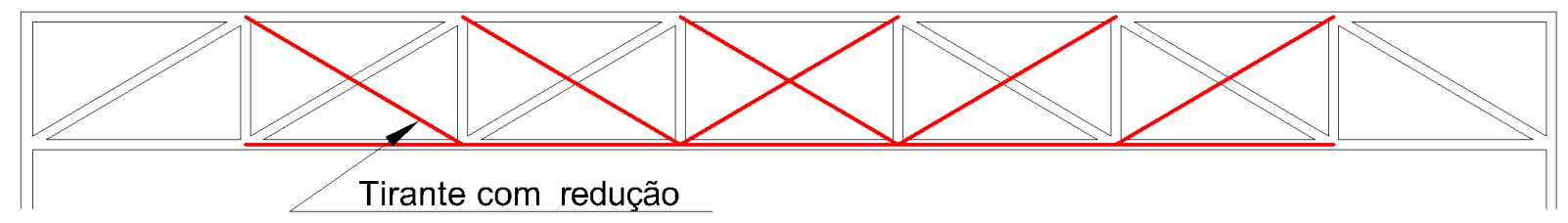

Figura 3: Localização do tirante com redução de seção.

\section{LEVANTAMENTO DAS MANIFESTAÇÕES PATOLÓGICAS}

No levantamento das manifestações patológicas verificou-se que alguns elementos metálicos se encontram corroídos sem redução significativa da seção transversal $(<10 \%)$ e oxidados e exigem um tratamento superficial com posterior pintura.

As calhas de concreto armado, que ficam em contato com as treliças, apresentam em todo o seu comprimento regiões com muita umidade, acelerando o processo corrosivo das barras de aço do concreto armado e dos tirantes de reforço das treliças. O intenso processo corrosivo instaurado nos tirantes de reforço ocasionou redução da seção transversal e ruptura por corrosão em um destes elementos, como pode ser observado na Figura 4, tal fato ocorreu em outras treliças e somente nos elementos que foram utilizados do reforço estrutural das treliças. No caso dos elementos já rompidos por corrosão, realizou-se a substituição imediata dos tirantes por novos elementos, assegurando a estabilidade da estrutura. 


\section{CBPAT 2020 \\ CONGRESSO BRASILEIRO DE PATOLOGIA DAS CONSTRUÇÕES \\ DE 15 A 17 DE ABRIL | FORTALEZA - CE}

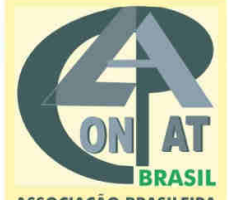

ISBN 978-65-86819-05-2 ASSOCIACĀO BRASILEIRA CONSTRUÇOES
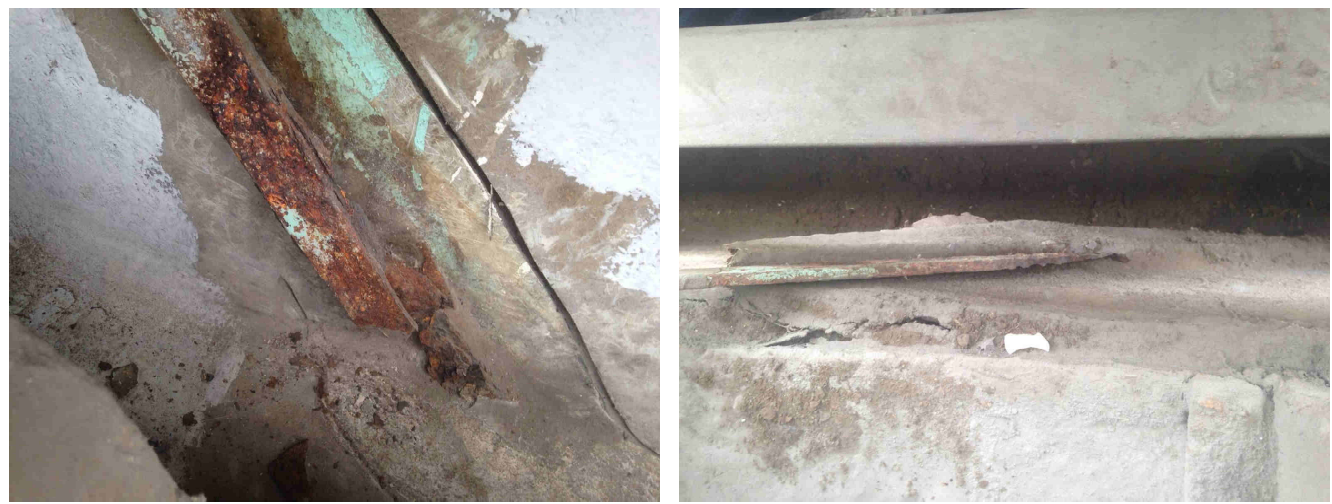

Figura 4: Ruptura do tirante de reforço por corrosão.

Como citado anteriormente uma das diagonais da Treliça 4 no Setor III apresentava uma redução do diâmetro inicial de $25 \mathrm{~mm}$ para $17 \mathrm{~mm}$, representado 32\% de redução da área da seção transversal, conforme demonstrado na Figura 5 . Por tratar-se de um tirante original da estrutura o rompimento desse elemento poderia ocasionar um possível colapso da estrutura, desta forma realizou-se uma análise estrutural para verificar as condições de segurança dessa treliça, considerando a redução do diâmetro deste elemento que está apresentado a seguir.

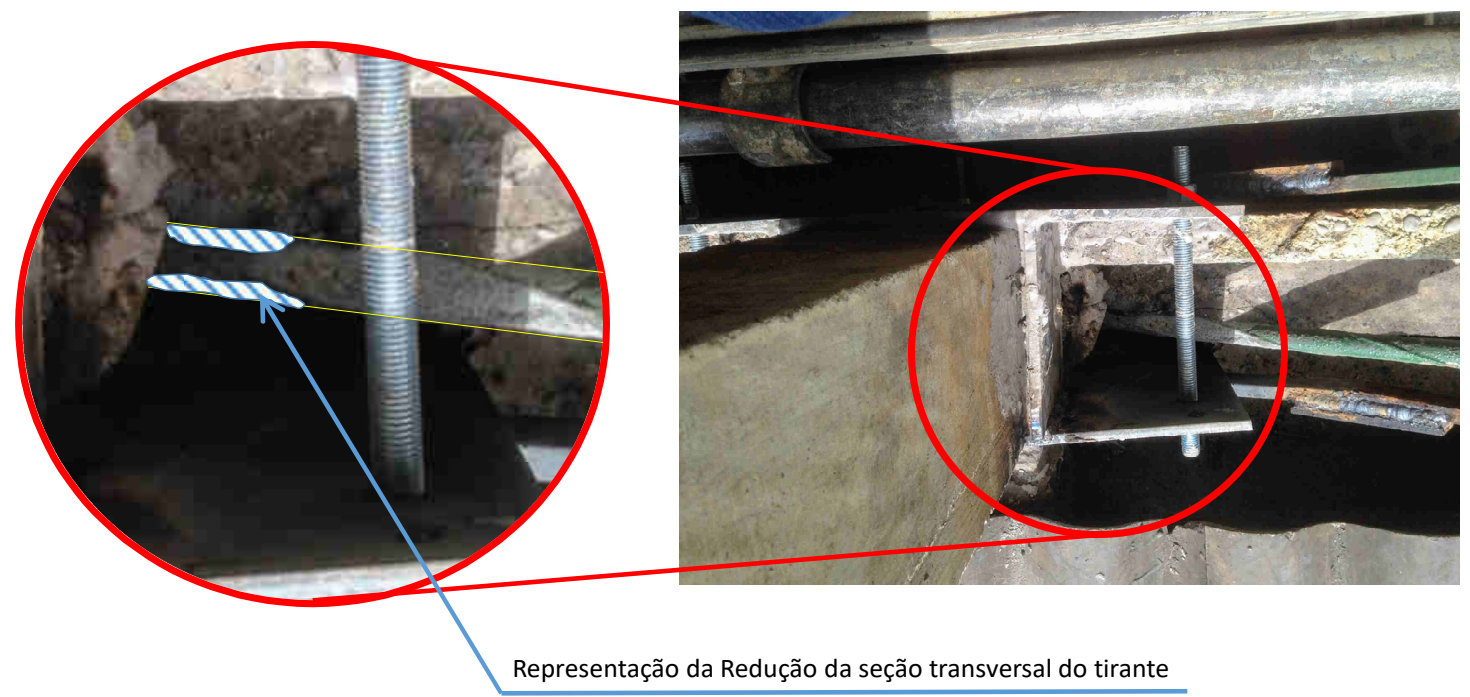

Figura 5: Detalhe da redução da seção transversal do tirante devido a corrosão.

\section{ANÁLISE ESTRUTURAL}

A análise linear elástica foi realizada considerando dois modelos estruturais distintos: modelo de treliça plana e modelo de pórtico plano, devido à elevada rigidez dos nós. No modelo de treliça (caso A) foi considerado o peso próprio da treliça distribuído igualmente pelos nós superiores, acrescentando em todos os nós da estrutura a carga devida às tesouras apoiadas, e as restantes cargas (telhas, sobrecarga de utilização, vento e terças) distribuídas, pelos nós superiores e inferiores, em função da área de influência.

No modelo de pórtico plano (caso B) o peso próprio da estrutura treliçada foi considerado linearmente distribuído nos elementos de barra e o peso próprio dos montantes foi concentrado no respectivo nó inferior. Foi acrescentada a carga devida às tesouras apoiadas em cada nó, e as restantes cargas (telhas, sobrecarga de utilização, vento e terças) foram distribuídas pelos nós em função da área de influência.

A estimativa das cargas atuantes teve por base a ABNT NBR 6120:2019 [6]. Para as cargas atuantes na cobertura foi considerado o peso próprio das telhas de fibrocimento, igual a $24 \mathrm{~kg} / \mathrm{m}^{2}$ e a ação do vento, igual a $23 \mathrm{~kg} / \mathrm{m}^{2}$, 
determinada de acordo com a ABNT NBR 6123:2013 [7], para o caso de sobrepressão, adotando para a velocidade característica do vento o valor de $45 \mathrm{~m} / \mathrm{s}$. Além destas cargas foi considerado, também, uma sobrecarga de utilização de $50 \mathrm{~kg} / \mathrm{m}^{2}$, referente à manutenção da cobertura. Para o peso específico do concreto armado foi adotado o valor de 2500 $\mathrm{kg} / \mathrm{m}^{3}$ e para o aço igual a $7800 \mathrm{~kg} / \mathrm{m}^{3}$. Foram adotados os valores para $\mathrm{f}_{\mathrm{ck}}$ de $15 \mathrm{MPa}$ e $\mathrm{f}_{\mathrm{yk}}$ igual a $250 \mathrm{MPa}$ e $500 \mathrm{MPa}$, respectivamente, para as resistências características do concreto, do aço liso CA-24 (assim como das chapas de aço de reforço) e do aço CA-50 das barras nervuradas. Não foram utilizados quaisquer coeficientes redutores de projeto.

Foram consideradas duas condições distintas para a seção do tirante que sofreu redução de seção no elemento "7": secção íntegra, de $1 \varnothing 25 \mathrm{~mm}$, e secção reduzida, devido a corrosão, de $1 \varnothing 17 \mathrm{~mm}$, conforme avaliado na inspeção da estrutura.

Não foram considerados coeficientes para ponderação das ações e das propriedades resistentes, nem coeficientes redutores associados a condições ambientais agressivas, (altas temperaturas e ataque de agentes químicos nocivos).

\subsection{Modelo de treliça plana com peso próprio distribuído nos nós superiores (caso A).}

A Figura 6 apresenta as cargas atuantes em cada um dos nós da estrutura treliçada, considerando o peso próprio da treliça distribuído pelos nós superiores, assim como a numeração dos elementos da estrutura.

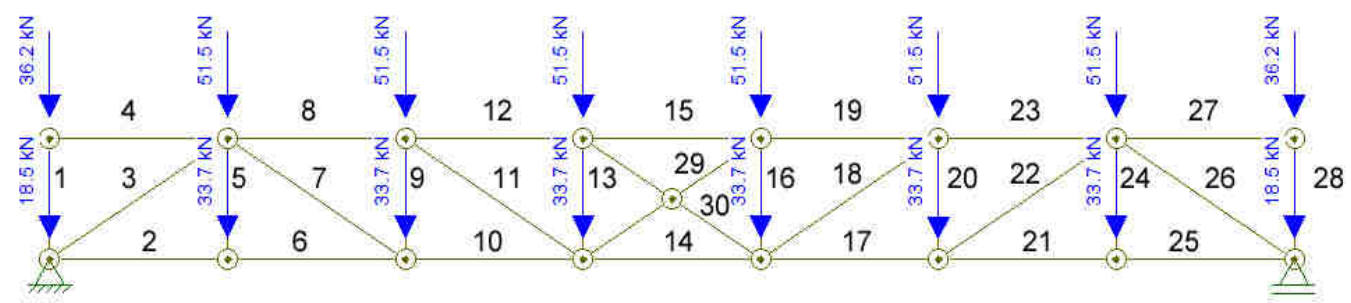

Figura 6: Modelo de treliça plana: cargas atuantes e numeração dos elementos

A Figura 7 apresenta os diagramas de esforços normais e a configuração deformada devida à aplicação do carregamento na estrutura treliçada.

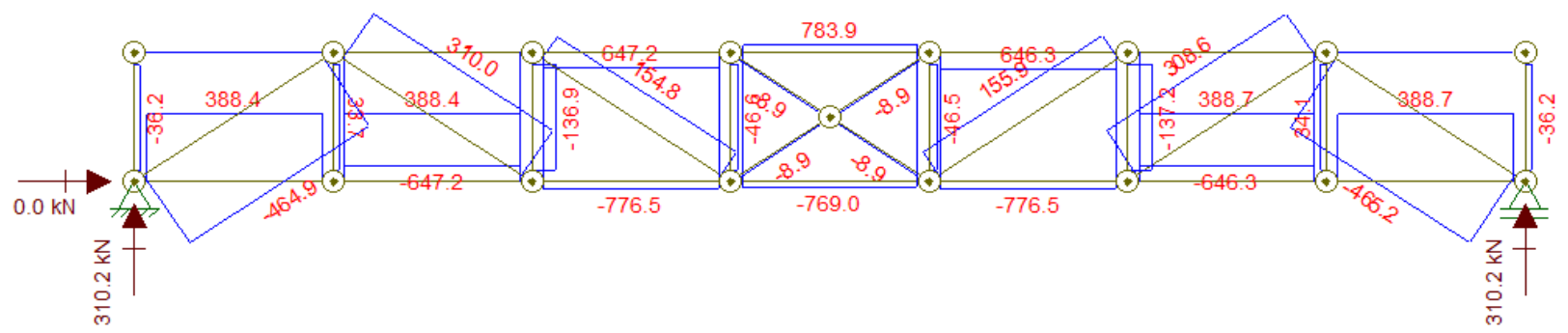

(a)

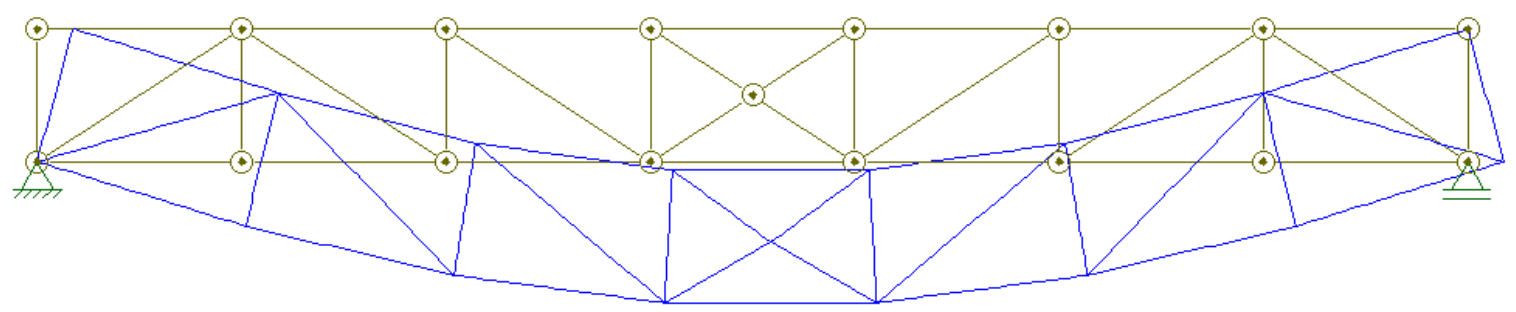

(b)

Figura 7: Modelo de treliça plana: (a) esforços axiais e (b) deformada

A Tabela 1 apresenta a verificação da capacidade de carga nos elementos da estrutura treliçada. Fator de segurança (F.S.) inferior a 1 significa que a carga aplicada no elemento estrutural é superior à carga máxima admissível, calculada com base na tensão máxima admissível, indicando que a estrutura não tem capacidade para suportar a carga aplicada. 
É possível observar na Tabela 1 que o tirante "7", considerando como seção resistente a barra de aço de seção reduzida mais o reforço das 2 chapas de aço, apresenta um F.S de 1,50. Todos os elementos possuem um F.S. superior a 1, incluindo o tirante corroído, porém, os elementos 12, 15 e 19 estão muito próximos da capacidade mínima portante.

Tabela 1 - Cargas atuantes, admissíveis e fatores de segurança na estrutura treliçada

\begin{tabular}{|c|c|c|c|c|c|c|c|}
\hline \multirow{2}{*}{ Barras } & \multirow[b]{2}{*}{$\begin{array}{l}\text { Dimensões } \\
(\mathrm{mm} \times \mathrm{mm})\end{array}$} & \multirow[b]{2}{*}{$\begin{array}{c}\text { Armaduras } \\
\varnothing / \text { aço }\end{array}$} & \multirow[b]{2}{*}{$\begin{array}{c}\mathrm{N} \\
(\mathrm{kN}) \\
\end{array}$} & \multicolumn{2}{|c|}{ Secção íntegra } & \multicolumn{2}{|c|}{ Secção reduzida } \\
\hline & & & & $\begin{array}{c}\mathrm{Nadm} \\
(\mathrm{kN})\end{array}$ & $\begin{array}{l}\text { F.S. } \\
\text { adim }\end{array}$ & $\begin{array}{c}\mathrm{Nadm} \\
(\mathrm{kN})\end{array}$ & $\begin{array}{c}\text { F.S. } \\
\text { adim }\end{array}$ \\
\hline 1 & $200 \times 200$ & $3 \varnothing 16+2 \varnothing 12,5$ & $-36,2$ & 812,2 & 22,44 & & \\
\hline 2 & Mista* & $2 \varnothing 19+2 \varnothing 10$ & 388,4 & 678,9 & 1,75 & & \\
\hline 3 & $200 \times 200$ & $4 \varnothing 16$ & $-464,9$ & 801,1 & 1,72 & & \\
\hline 4 & $200 \times 200$ & $4 \varnothing 16$ & 0,0 & NA & NA & & \\
\hline 5 & $200 \times 200$ & $6 \varnothing 10$ & 33,7 & 177,8 & 5,28 & & \\
\hline 6 & Mista* & $2 \varnothing 19+2 \varnothing 10$ & 388,4 & 678,9 & 1,75 & & \\
\hline 7 & $1 \varnothing 25+2$ chapas & $\begin{array}{c}\varnothing 25+2 \text { chapas } \\
(44,4 \times 15,9 \mathrm{~mm} 2)\end{array}$ & 310,0 & 600,8 & 1,94 & 466,5 & 1,50 \\
\hline 8 & $200 \times 200$ & $4 \varnothing 16$ & $-647,2$ & 801,1 & 1,24 & & \\
\hline 9 & $200 \times 200$ & $4 \varnothing 10$ & $-136,9$ & 678,5 & 4,96 & & \\
\hline 10 & Mista* & $\begin{array}{c}2 \varnothing 19+1 \varnothing 25+ \\
2 \varnothing 10 \\
\end{array}$ & 647,2 & 801,6 & 1,24 & & \\
\hline 11 & $1 \varnothing 22+2$ chapas & $\begin{array}{c}1 \varnothing 22+2 \text { chapas } \\
(44,4 \times 15,9 \mathrm{~mm} 2)\end{array}$ & 154,8 & 545,4 & 3,52 & & \\
\hline 12 & $200 \times 200$ & $4 \varnothing 16$ & $-776,5$ & 801,1 & 1,03 & & \\
\hline 13 & $200 \times 200$ & $4 \varnothing 10$ & $-46,6$ & 678,5 & 14,56 & & \\
\hline 14 & Mista* & $\begin{array}{c}3 \varnothing 19+1 \varnothing 25+ \\
2 \emptyset 10\end{array}$ & 783,9 & 872,5 & 1,11 & & \\
\hline 15 & $200 \times 200$ & $4 \varnothing 16$ & $-769,0$ & 801,1 & 1,04 & & \\
\hline 16 & $200 \times 200$ & $4 \varnothing 10$ & $-46,5$ & 678,5 & 14,59 & & \\
\hline 17 & Mista* & $\begin{array}{c}2 \varnothing 19+1 \varnothing 25+ \\
2 \varnothing 10\end{array}$ & 646,3 & 801,6 & 1,24 & & \\
\hline 18 & $1 \varnothing 22+2$ chapas & $\begin{array}{c}1 \emptyset 22+2 \text { chapas } \\
(44,4 \times 15,9 \mathrm{~mm} 2)\end{array}$ & 155,9 & 545,4 & 3,50 & & \\
\hline 19 & $200 \times 200$ & $4 \varnothing 16$ & $-776,5$ & 801,1 & 1,03 & & \\
\hline 20 & $200 \times 200$ & $4 \varnothing 10$ & $-137,2$ & 678,5 & 4,95 & & \\
\hline 21 & Mista* & $2 \varnothing 19+2 \varnothing 10$ & 388,7 & 678,9 & 1,75 & & \\
\hline 22 & $1 \emptyset 25+2$ chapas & $\begin{array}{l}1 \varnothing 25+2 \text { chapas } \\
(44,4 \times 15,9 \mathrm{~mm} 2)\end{array}$ & 308,6 & 600,8 & 1,95 & & \\
\hline 23 & $200 \times 200$ & $4 \varnothing 16$ & $-646,3$ & 801,1 & 1,24 & & \\
\hline 24 & $200 \times 200$ & $6 \varnothing 10$ & 34,1 & 177,8 & 5,21 & & \\
\hline 25 & Mista* & $2 \varnothing 19+2 \varnothing 10$ & 388,7 & 678,9 & 1,75 & & \\
\hline 26 & $200 \times 200$ & $4 \varnothing 16$ & $-465,2$ & 801,1 & 1,72 & & \\
\hline 27 & $200 \times 200$ & $4 \varnothing 16$ & 0,0 & NA & NA & & \\
\hline 28 & $200 \times 200$ & $4 \varnothing 16$ & $-36,2$ & 801,1 & 22,13 & & \\
\hline 29 & 2 chapas & $(44,4 \times 15,9 \mathrm{~mm} 2)$ & $-8,9$ & 355,3 & 39,93 & & \\
\hline 30 & 2 chapas & $(44,4 \times 15,9 \mathrm{~mm} 2)$ & $-8,9$ & 355,3 & 39,93 & & \\
\hline
\end{tabular}

(*) área de concreto armado equivalente a $95000 \mathrm{~mm}^{2}+2$ chapas $(44,5 \times 15,97)$

\subsection{Modelo de pórtico plano e peso próprio distribuído linearmente (caso B).}

A Figura 8 apresenta as cargas atuantes na estrutura porticada (caso B). 


\section{СВРAT 2020 \\ CONGRESSO BRASILEIRO DE PATOLOGIA DAS CONSTRUÇÕES \\ DE 15 A 17 DE ABRIL | FORTALEZA - CE}

ISBN 978-65-86819-05-2

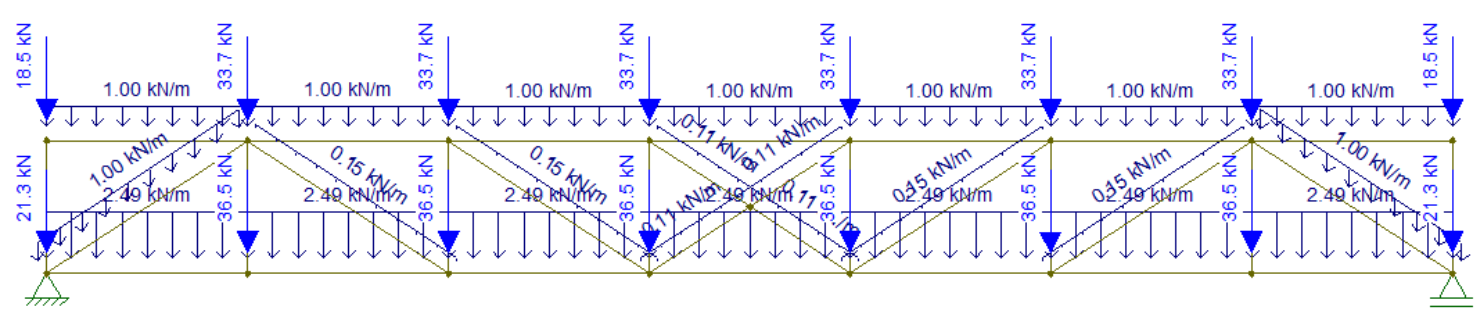

Figura 8: Modelo de pórtico plano (caso B): cargas atuantes

A Figura 9 apresenta os diagramas de esforços normais e esforços cortantes e a Figura 10 apresenta os diagramas de momentos fletores e a configuração deformada devida à aplicação do carregamento na estrutura considerada como um pórtico (caso B).

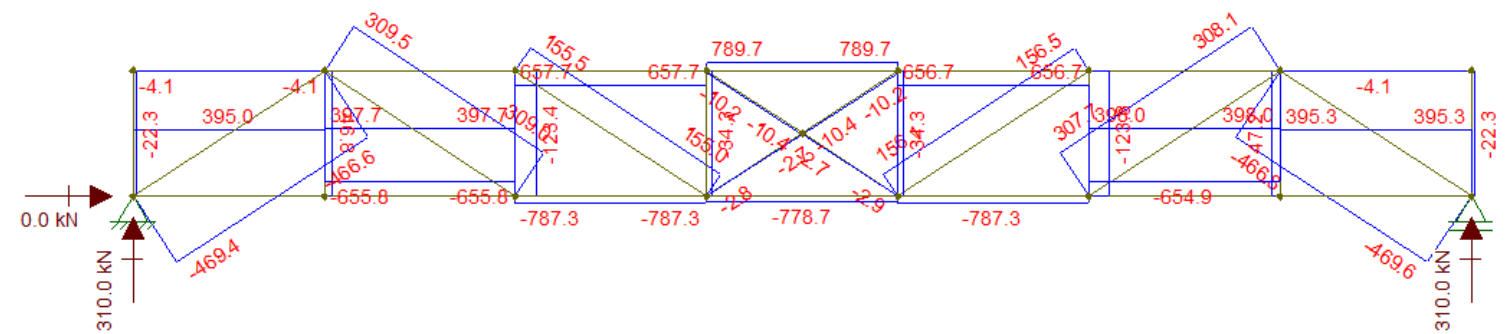

(a)

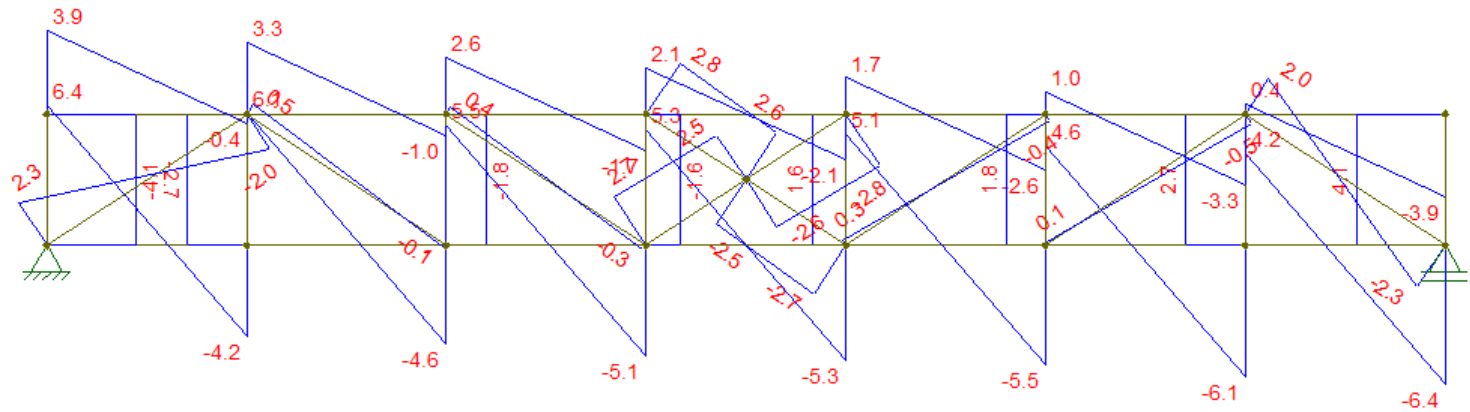

(b)

Figura 9: Modelo de pórtico plano (caso B): a) esforços normais e b) esforços cortantes

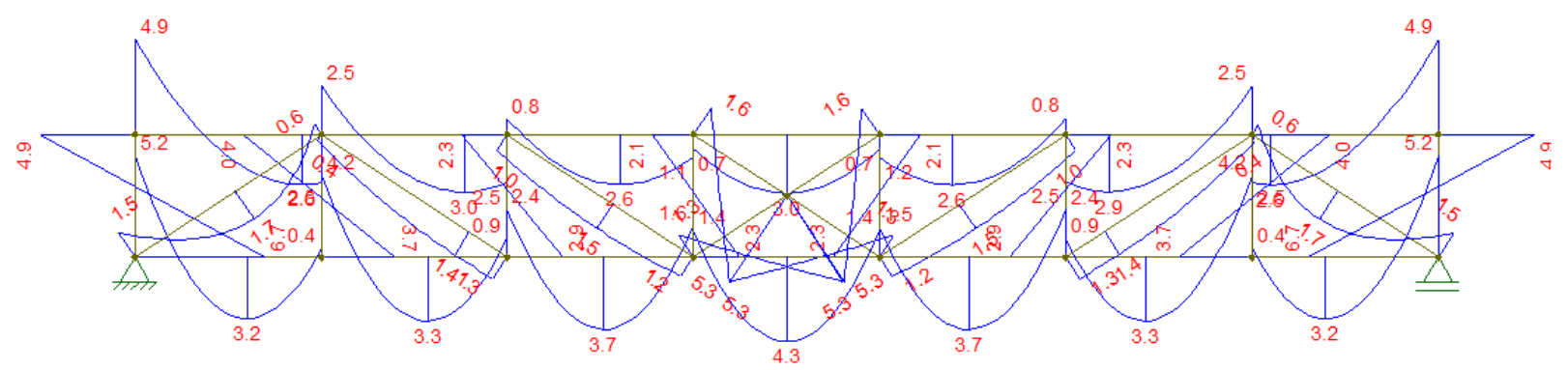

(a)

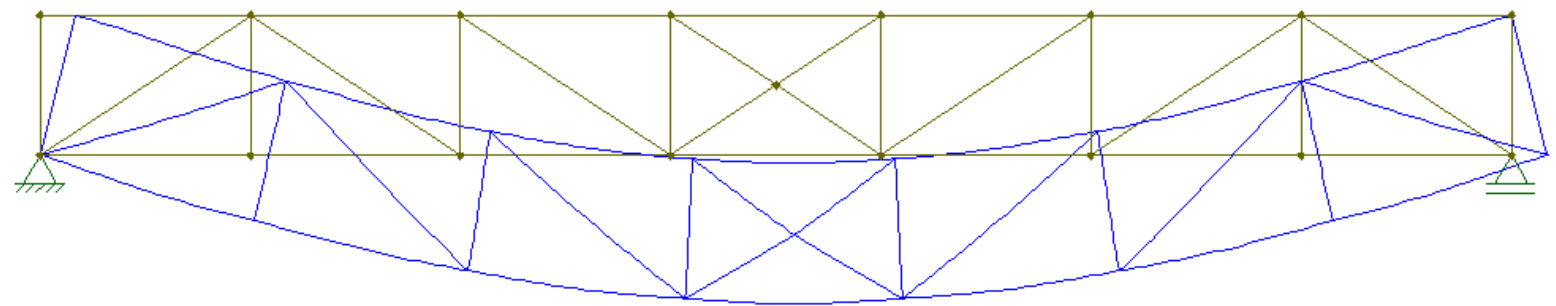

(b)

Figura 10: Modelo de pórtico plano (caso B): a) momentos fletores e b) deformada 
A Tabela 2 apresenta a verificação da capacidade de carga nos elementos da estrutura porticada (caso B). Fator de segurança (F.S.) inferior a 1 significa que a carga aplicada no elemento estrutural é superior à carga máxima admissível, calculada com base na tensão máxima admissível.

É possível observar na Tabela 2 que o tirante 7, considerando como seção resistente a barra de aço de seção reduzida mais o reforço das 2 chapas de aço, apresenta F.S. igual a 1,51. Tal como no caso anterior, todos os elementos possuem F.S. superior a 1, incluindo o tirante corroído, porém, os elementos 12, 15 e 19 estão muito próximos da capacidade portante mínima.

Tabela 2 - Cargas atuantes, admissíveis e fatores de segurança na estrutura porticada.

\begin{tabular}{|c|c|c|c|c|c|c|c|}
\hline \multirow{2}{*}{ Barras } & \multirow[b]{2}{*}{$\begin{array}{l}\text { Dimensões } \\
(\mathrm{mm} \times \mathrm{mm})\end{array}$} & \multirow[b]{2}{*}{$\begin{array}{c}\text { Armaduras } \\
\varnothing / \text { aço }\end{array}$} & \multirow[b]{2}{*}{$\begin{array}{c}\mathrm{N} \\
(\mathrm{kN})\end{array}$} & \multicolumn{2}{|c|}{ Secção íntegra } & \multicolumn{2}{|c|}{ Secção reduzida } \\
\hline & & & & $\begin{array}{c}\mathrm{Nadm} \\
(\mathrm{kN})\end{array}$ & $\begin{array}{l}\text { F.S. } \\
\text { adim }\end{array}$ & $\begin{array}{c}\mathrm{Nadm} \\
(\mathrm{kN})\end{array}$ & $\begin{array}{l}\text { F.S. } \\
\text { adim }\end{array}$ \\
\hline 1 & $200 \times 200$ & $3 \varnothing 16+2 \varnothing 12,5$ & $-22,3$ & 812,2 & 36,42 & & \\
\hline 2 & Mista* & $2 \varnothing 19+2 \emptyset 10$ & 395,0 & 678,9 & 1,72 & & \\
\hline 3 & $200 \times 200$ & $4 \varnothing 16$ & $-467,5$ & 801,1 & 1,71 & & \\
\hline 4 & $200 \times 200$ & $4 \varnothing 16$ & $-4,1$ & 801,1 & 195,38 & & \\
\hline 5 & $200 \times 200$ & $6 \varnothing 10$ & 46,8 & 177,8 & 3,80 & & \\
\hline 6 & Mista* & $2 \varnothing 19+2 \emptyset 10$ & 397,7 & 678,9 & 1,71 & & \\
\hline 7 & $1 \emptyset 25+2$ chapas & $\begin{array}{c}1 \varnothing 25+2 \text { chapas } \\
(44,4 \times 15,9 \mathrm{~mm} 2)\end{array}$ & 309,4 & 600,8 & 1,94 & 466,5 & 1,51 \\
\hline 8 & $200 \times 200$ & $4 \varnothing 16$ & $-655,8$ & 801,1 & 1,22 & & \\
\hline 9 & $200 \times 200$ & $4 \varnothing 10$ & $-123,4$ & 678,5 & 5,50 & & \\
\hline 10 & Mista* & $\begin{array}{c}2 \varnothing 19+1 \varnothing 25+ \\
2 \varnothing 10\end{array}$ & 657,7 & 801,6 & 1,22 & & \\
\hline 11 & $1 \emptyset 22+2$ chapas & $\begin{array}{c}1 \varnothing 22+2 \text { chapas } \\
(44,4 \times 15,9 \mathrm{~mm} 2)\end{array}$ & 155,2 & 545,4 & 3,51 & & \\
\hline 12 & $200 \times 200$ & $4 \varnothing 16$ & $-787,3$ & 801,1 & 1,02 & & \\
\hline 13 & $200 \times 200$ & $4 \varnothing 10$ & $-34,3$ & 678,5 & 19,78 & & \\
\hline 14 & Mista* & $\begin{array}{c}3 \varnothing 19+1 \varnothing 25+ \\
2 \varnothing 10\end{array}$ & 789,7 & 872,5 & 1,10 & & \\
\hline 15 & $200 \times 200$ & $4 \varnothing 16$ & $-778,7$ & 801,1 & 1,03 & & \\
\hline 16 & $200 \times 200$ & $4 \varnothing 10$ & $-34,3$ & 678,5 & 19,78 & & \\
\hline 17 & Mista* & $\begin{array}{c}2 \varnothing 19+1 \varnothing 25+ \\
2 \emptyset 10\end{array}$ & 656,7 & 801,6 & 1,22 & & \\
\hline 18 & $1 \varnothing 22+2$ chapas & $\begin{array}{c}1 \emptyset 22+2 \text { chapas } \\
(44,4 \times 15,9 \mathrm{~mm} 2)\end{array}$ & 156,4 & 545,4 & 3,49 & & \\
\hline 19 & $200 \times 200$ & $4 \varnothing 16$ & $-787,3$ & 801,1 & 1,02 & & \\
\hline 20 & $200 \times 200$ & $4 \varnothing 10$ & $-123,8$ & 678,5 & 5,48 & & \\
\hline 21 & Mista* & $2 \varnothing 19+2 \emptyset 10$ & 398,0 & 678,9 & 1,71 & & \\
\hline 22 & $1 \varnothing 25+2$ chapas & $\begin{array}{l}1 \emptyset 25+2 \text { chapas } \\
(44,4 \times 15,9 \mathrm{~mm} 2)\end{array}$ & 308,0 & 600,8 & 1,95 & & \\
\hline 23 & $200 \times 200$ & $4 \varnothing 16$ & $-654,9$ & 801,1 & 1,22 & & \\
\hline 24 & $200 \times 200$ & $6 \varnothing 10$ & 47,2 & 177,8 & 3,77 & & \\
\hline 25 & Mista* & $2 \varnothing 19+2 \emptyset 10$ & 395,3 & 678,9 & 1,72 & & \\
\hline 26 & $200 \times 200$ & $4 \varnothing 16$ & $-468,8$ & 801,1 & 1,71 & & \\
\hline 27 & $200 \times 200$ & $4 \varnothing 16$ & $-4,1$ & 801,1 & 195,38 & & \\
\hline 28 & $200 \times 200$ & $4 \varnothing 16$ & $-22,3$ & 801,1 & 35,92 & & \\
\hline 29 & 2 chapas & $(44,4 \times 15,9 \mathrm{~mm} 2)$ & $-10,3$ & 355,3 & 34,50 & & \\
\hline 30 & 2 chapas & $(44,4 \times 15,9 \mathrm{~mm} 2)$ & $-10,3$ & 355,3 & 34,50 & & \\
\hline
\end{tabular}

(*) área de concreto armado equivalente a $95000 \mathrm{~mm} 2+2$ chapas $(44,5 \times 15,97)$ 
Os resultados teóricos obtidos para o modelo de pórtico plano foram próximos aos obtidos considerando o modelo de treliça plana. Considerando a ação do vento e a sobrecarga para manutenção da cobertura, a estabilidade estrutural nos elementos mais solicitados à compressão, elementos 12,15 e 19, tem uma margem de segurança mínima, conforme ilustrado na cor laranja, na Figura 11.

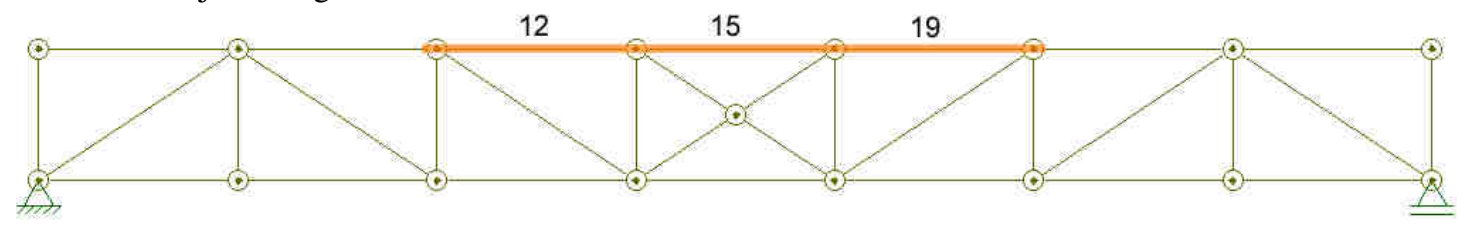

Figura 11: Modelo de treliça plana: elementos com margem mínima de segurança (F.S. $\approx 1)$.

\section{CONSIDERAÇÕES FINAIS}

$\mathrm{Na}$ inspeção realizada foi possível identificar o principal mecanismo de degradação estrutural da cobertura treliçada em concreto armado reforçada com tirantes de aço, especificamente, a corrosão com redução de seção resistente em um dos tirantes de reforço. A falta de manutenção e exposição a ambiente agressivo poderão ser apontadas como as principais causas desta manifestação patológica.

No cálculo teórico o modelo de treliça e modelo de pórtico apresentaram resultados muito próximos. Os valores teóricos apontam que, considerando a ação do vento e a sobrecarga para manutenção da cobertura, a estrutura possui capacidade portante mínima nos elementos mais solicitados, já que o fator de segurança está muito próximo a 1.

O presente estudo evidencia a importância da inspeção e da verificação estrutural, dentro do âmbito da implementação e manutenção de um plano de inspeções e manutenções programadas, adequado à edificação, de forma a poder melhorar o atual nível de desempenho e prolongar a vida útil da estrutura.

\section{REFERÊNCIAS}

[1] ASSOCIAÇÃO BRASILEIRA DE NORMAS TÉCNICAS. NBR 16230: Inspeção de estruturas de concreto Qualificação e certificação de pessoal — Requisitos. Rio de Janeiro, 2013.

[2] DAL MOLIN, D. C. C. Patologia das estruturas de concreto. Programa de Pós-graduação em Engenharia Civil , Curso de Doutorado em Engenharia Civil, UFRGS. Porto Alegre-RS, 2000. Notas de aula.

[3] CASCUDO, O.; HELENE, P. R. L. Resistência à corrosão no concreto dos tipos de armaduras brasileiras para concreto armado. BT/PCC/272. São Paulo, 2001.

[4] MEIRA, G. R. Corrosão de armaduras em estruturas de concreto - Fundamentos, Diagnóstico e Prevenção. Editora IFPB, 130 pp. João Pessoa, 2017.

[5] ABNT NBR 6118: Projeto de estruturas de concreto — Procedimento. Rio de Janeiro, 2014.

[6] ASSOCIAÇÃO BRASILEIRA DE NORMAS TÉCNICAS. NBR 6120: Ações para o cálculo de estruturas de edificações. Rio de Janeiro, 2019.

[7] ASSOCIAÇÃO BRASILEIRA DE NORMAS TÉCNICAS. NBR 6123: Forças devidas ao vento em edificações. Rio de Janeiro, 2013. 